\title{
Immune checkpoint inhibitors in liver transplant recipients - a review of current literature
}

\author{
Chao Yin ${ }^{1, \#}$, Tilak Baba ${ }^{2, \#}$, Aiwu Ruth He${ }^{1}$, Coleman Smith ${ }^{2}$ \\ 'Lombardi Comprehensive Cancer Center, Georgetown University Medical Center, Washington, DC 20007, USA. \\ ${ }^{2}$ MedStar Georgetown Transplant Center, Georgetown University Medical Center, Washington, DC 20007, USA. \\ \#The authors are co-first authors.
}

Correspondence to: Dr. Coleman Smith, MedStar Georgetown Transplant Center, Georgetown University Medical Center, 3800 Reservoir Rd NW, Washington, DC 20007, USA. E-mail: coleman.i.smith@gunet.georgetown.edu

How to cite this article: Yin C, Baba T, He AR, Smith C. Immune checkpoint inhibitors in liver transplant recipients - a review of current literature. Hepatoma Res 2021;7:52. https://dx.doi.org/10.20517/2394-5079.2021.11

Received: 31 Jan 2021 First Decision: 7 Apr 2021 Revised: 14 May 2021 Accepted: 2 Jun 2021 Available online: 8 Jun 2021

Academic Editors: Guang-Wen Cao, James Fung Copy Editor: Yue-Yue Zhang Production Editor: Yue-Yue Zhang

\begin{abstract}
Immuno-oncology, particularly with the development of immune checkpoint inhibitors (ICls), has become a frontline category of cancer-directed therapy, including in the treatment of hepatocellular carcinoma (HCC). While liver transplant (LT) offers a potential cure for HCC, the use of ICls is a topic of safety concern both pre- and posttransplant due to the risk of donor graft rejection. Nonetheless, some scenarios for which the therapeutic effects of $\mathrm{ICI}$ may be highly beneficial include the downstaging of unresectable HCC pre-transplant, or the treatment of recurrent $\mathrm{HCC}$ and secondary malignancies post-transplant. In this review, we explored the evidence surrounding the use of $\mathrm{ICl}$ in the peri-transplant setting, including safety and efficacy. In a comprehensive review of 28 cases of $\mathrm{ICl}$ use post-transplant, we found graft rejection in 9 of 28 cases (32\%). Some factors that may increase the risk of rejection include younger age, less time between LT and ICI therapy, and PD-1/PD-L1 expression in the donor graft (particularly when using anti-PD-1/anti-PD-L1 ICls). Despite these concerns, we relay a case of successful HCC downstaging with nivolumab and subsequent LT. We also describe several cases of response to ICls post-LT (7 of 28 cases) among a group that is often heavily pre-treated. We conclude that $\mathrm{ICls}$ are valuable options in the peritransplant setting that have demonstrated promising efficacy based on case reports. Controlled clinical trials are needed to further investigate the conditions that may allow safe delivery of these therapies.
\end{abstract}

Keywords: Immunotherapy, immune checkpoint inhibitors, CTLA-4 inhibitors, PD-1 inhibitors, hepatocellular carcinoma, liver transplant, allograft rejection 


\section{INTRODUCTION}

Hepatocellular carcinoma (HCC) is the primary liver tumor and the fourth leading cause of cancer-related death worldwide ${ }^{[1]}$. Incidence of this disease has steadily increased over the last several years ${ }^{[2]}$. Established surveillance guidelines have enabled the detection of HCC at an earlier stage. Still, despite these guidelines, a significant number of patients are diagnosed with HCC at an advanced stage when curative therapies are not an option. Systemic chemotherapy using sorafenib was the only standard of care available for patients with advanced HCC for several years; however, multiple alternative agents have now been approved as first line, including lenvatinib. Various second-line therapies have also been approved for HCC; these include several immune checkpoint inhibitors (ICIs), which fall under the broader category of immuno-oncology. While there is an established role for ICIs in advanced disease, there are no clear guidelines or protocols for their use in the peri-transplant setting. There is a higher risk of de novo malignancies in liver transplant recipients on immunosuppression. These include skin cancer (with an increased risk of up to 70\%); lung, colorectal, and kidney cancers; and recurrent $\mathrm{HCC}^{[3]}$. The role of IO in many of these malignancies is well established in non-transplant patients, but data is limited in solid organ transplant recipients.

The primary concern for the peri-transplant use of ICI is the risk of graft rejection. It is believed that the programmed death 1 (PD-1) and cytotoxic T-lymphocyte-associated antigen-4 (CTLA4) pathways facilitate immune tolerance of the graft; PD-L1 is expressed in post-transplant liver allografts and PD-1 is heavily expressed on graft-infiltrating T-cells ${ }^{[4,5]}$. Similarly, binding of CTLA4 on T-cells to its counter-receptor B7 provides an inhibitory signal that terminates $\mathrm{T}$-cell responses ${ }^{[6,7]}$. Hence, blockade of these pathways may trigger prolific activity of these T-cells, resulting in a T-cell mediated graft rejection. However, based on the limited body of evidence we have reviewed, we hypothesize that there are certain favorable conditions in which ICI use may lend to a decreased chance of graft rejection.

In this review, we will discuss the role of ICI's in the peri-transplant setting, their safety, and their efficacy.

\section{IMMUNE CHECKPOINT INHIBITOR THERAPY PRE-TRANSPLANT}

Patients with HCC diagnosed beyond Milan criteria are often treated locoregionally with radiofrequency ablation, transarterial chemoembolization (TACE), or transarterial radioembolization ${ }^{[8]}$. There is a growing interest in combining systemic with locoregional therapy to downstage these patients and make them eligible for liver transplant (LT) ${ }^{[9]}$. However, there are limited data on the role of neoadjuvant systemic treatment, including IO in the liver transplant setting. Sorafenib was FDA-approved for treating patients with advanced HCC in 2008, based on a modest improvement in overall survival (OS) compared to placebo (10.7 months vs. 7.9 months) ${ }^{[10]}$. Thereafter, the advanced HCC therapeutic arsenal expanded past sorafenib to include lenvatinib and combined atezolizumab plus bevacizumab as first line therapy and tyrosine kinase inhibitors regorafenib and cabozantinib and ICIs nivolumab and pembrolizumab as second line therapy ${ }^{[11]}$. However, to date, only sorafenib has been studied in the neoadjuvant setting, but prospective trials have failed to demonstrate any benefit in OS or disease outcome according to RECIST criteria ${ }^{[12,13]}$.

Now that ICIs have a niche in the standard treatment algorithm for advanced $\mathrm{HCC}^{[11]}$, there is growing interest in their neoadjuvant use prior to LT. So far, only two case reports have been published in this domain. First, Nordness et al. ${ }^{[14]}$ reported a case of poor outcome in a 65 -year-old male with HCC within Milan criteria, who quickly failed sorafenib therapy and was initially declined a LT due to up-trending blood alpha fetoprotein (AFP) levels. These levels reached as high as $2500 \mathrm{ng} / \mathrm{mL}$ when the patient began treatment with nivolumab (intended as a destination therapy) for almost 2 years before undergoing TACE. This ICI plus TACE strategy maintained the patient's disease within Milan criteria, reducing his AFP levels to $2.3 \mathrm{ng} / \mathrm{mL}$ and allowing him to undergo LT 8 days after his last dose of nivolumab. The patient's 
postoperative course, which included a standard immunosuppressant drug regimen of tacrolimus, mycophenolate, and prednisone, was unfortunately complicated by signs of profound liver injury on postoperative day (POD) 2. A liver biopsy on POD 6 demonstrated acute hepatic necrosis with profound lymphocyte infiltration, consistent with graft rejection. Despite the initiation of high-dose immunosuppression (methylprednisolone $1000 \mathrm{mg} /$ day and rabbit anti-thymocyte globulin, he expired on POD 10.

In another case reported by Schwacha-Eipper et al. ${ }^{[15]}$, a 65 -year-old male had a good outcome with neoadjuvant nivolumab followed by LT. He was diagnosed beyond Milan criteria and was started on nivolumab after progression on sorafenib for 14 months. He continued nivolumab for 34 cycles (> 1 year) and had a good partial response with successful downstaging of his cancer, after which he was reevaluated for LT. Due to concern over nivolumab-induced transplant rejection, nivolumab was stopped 6 weeks before listing the patient for transplantation. He was 15 weeks out from his last nivolumab dose when he received a LT. He continues to do well without any evidence of disease recurrence when last reported, one year after surgery.

Given the low sample size, we can only conclude from the two cases reported here that downstaging of HCC for transplant via neoadjuvant IO is feasible in a select population, although the risk of graft rejection poses a real concern. One of the glaring differences between these cases is the timing of the last dose of nivolumab with respect to liver transplantation. A shorter period between the last dose of ICI and LT (8 days vs. 15 weeks) may increase the risk of graft rejection. The long-lasting effects of ICIs have been well described. In HCC, pembrolizumab had a median duration of response (DOR) of 13.8 months in KEYNOTE-240, while nivolumab +/- ipilimumab had a median DOR of 17 months in CHECKMATE$040^{[16-18]}$. The lasting effects of ICIs are supported by the delayed appearance of adverse events (AEs). The time to onset of ICI AEs varies by organ sites but is generally in the order of weeks to months. For example, the median time to hepatotoxicity is 3 to 9 weeks, and the median time to pneumonitis is about 2.5 months (but may take up to 24 months $)^{[19-21]}$. Furthermore, nivolumab and pembrolizumab have long half-lives $(\sim 25$ days $)^{[22]}$. Usually, it takes 4 to 5 half-lives for plasma concentrations of any given drug to drop below clinically relevant concentrations. We hypothesize that the optimal timing of transplant after the last dose of ICI would be in the order of months, which should take a patient outside of the risk period of the majority of liver-related adverse events, possibly including toxicity to the liver graft. Even so, any lasting effects of ICIs after plasma elimination still need to be determined.

\section{IMMUNE CHECKPOINT INHIBITOR THERAPY POST LIVER TRANSPLANT}

Despite increasingly stringent criteria guiding the selection of transplant candidates (i.e., Milan criteria), recurrence of HCC occurs in up to $15 \%-20 \%$ of liver transplant recipients ${ }^{[23-26]}$. Median survival after recurrence is only around 12 months ${ }^{[25,26]}$. There is no formal consensus on the appropriate treatment at the time of recurrence. Sorafenib has been commonly used in this scenario, mostly because of concerns related to IO use in a transplant patient on immunosuppressants. However, there is growing interest in exploring IO as a treatment option in this population, especially following the recent ICI approvals for patients with advanced $\mathrm{HCC}^{[1,2,27,28]}$. Graft recipients are still suspectable to the development of secondary malignancies such as melanoma and lung cancer. In one meta-analysis, investigators found that melanoma was 2.71 times more common in solid organ transplant patients and potentially related to the use of immunosuppressive therapies ${ }^{[29]}$. Melanoma and lung cancers are now preferably treated with $\mathrm{IO}^{[30,31]}$, but, to date, there have been no formal recommendations regarding the use of IO post-transplant, although several case reports document the application of these agents in this setting. 
A summary of 28 cases of liver transplant recipients who went on to receive IO is shown in Table 1; this is the most comprehensive list to dat $\mathrm{e}^{[32-50]}$. HCC was the reason for LT in 22 of these cases. The most common indications for post-transplant IO were recurrent HCC (18 cases) and malignant melanoma (7 cases). Out of all 28 reviewed cases, 4 patients had a confirmed complete response (CR), and 3 had partial responses to IO. Twelve cases had progression of disease after ICI use, and 9 had unknown responses. Specifically, for those with recurrent HCC, 2 of 18 patients had complete responses, and no partial responses were described. Both HCC patients who responded demonstrated durability of these treatment effects, with CR lasting beyond the time of their respective case reports at $>10$ months and $>1.5$ years. Reportedly, all patients had received at least sorafenib and often had further lines of therapy for HCC prior to receiving IO. As a point of reference, investigators of the Phase II KEYNOTE-224 and phase III KEYNOTE-240 trials described an objective response rate (ORR) in non-transplant HCC patients treated with subsequent-line pembrolizumab of $17 \%$ and $18 \%$, respectively ${ }^{[17,27]}$. Of the 7 melanoma cases shown in Table 1, 2 patients had complete responses, and 2 had partial responses to therapy. When these response data are compared with data from non-transplant patients with advanced melanoma in the Phase III CHECKMATE-066 and KEYNOTE-006 trials, in which nivolumab and pembrolizumab monotherapy were used to treat advanced melanoma, with a $\sim 40 \%$ ORR and $\sim 15 \% \mathrm{CR}^{[1,52]}$, it can be seen that response data are similar. Hence, recurrent HCC or melanoma in liver transplant recipients can respond to IO.

\section{ADVERSE EVENTS}

Immune checkpoint inhibitor (ICI) therapy is associated with a spectrum of adverse effects categorized as immune-related adverse events (irAEs) ${ }^{[53]}$. These toxicities are generally considered distinct from traditional chemotherapy-related adverse effects. The irAEs caused by ICI therapy result from the infiltration of activated $\mathrm{T}$ cells into normal tissues. Various organ systems can potentially be affected by ICI treatment; nevertheless, previous ICI trials in HCC have shown these agents to be reasonably well tolerated. Nivolumab demonstrated an acceptable safety profile in Phase I/II and Phase III trials ${ }^{[1,54]}$. Pembrolizumab has similar safety data ${ }^{[27]}$, as does durvalumab, which is the only anti-PD-L1 monoclonal antibody being studied in HCC, although only Phase I/II trial data is available ${ }^{[55]}$. It has also been suggested that antitumor response can be enhanced using combinations of drugs with different molecular targets. Thirty-eight percent of HCC patients receiving combined nivolumab plus ipilimumab (anti-CTLA-4 antibody) therapy developed Grade 3/4 treatment-related adverse events. However, only 5\% of patients required treatment discontinuation ${ }^{[56]}$. ICI therapy is now also used in combination with vascular endothelial growth factor A. The recently FDA-approved regimen of atezolizumab plus bevacizumab induced grade $3 / 4$ adverse events in $56 \%$ of treated patients, but very few patients required related discontinuation of treatment ${ }^{[28]}$.

Hepatotoxicity is one of the most concerning irAEs related to ICI use. The most common form of liver injury is hepatitis, which is characterized by a marked elevation in aminotransferases with or without an elevation in bilirubin levels. The onset of liver injury is typically within several weeks of therapy initiation. The severity of hepatitis is related to the degree of elevation in aminotransferase and bilirubin levels. The prevalence of hepatic injury related to ICI monotherapy use ranges from $2 \%-10 \%$ in various clinical trials ${ }^{[57]}$. Significant liver toxicity (Grade 3/4) is rare. However, combination ICI therapy has been associated with higher rates of hepatotoxicity ${ }^{[58]}$, an observation that is likely related to anti-CTLA4 therapy, which reportedly has greater toxicity than PD-1 or PD-L1 inhibitors ${ }^{[59]}$. Severe hepatotoxicity is typically treated with high dose corticosteroids, and the majority of patients respond well to this treatment ${ }^{[60]}$.

\section{IMMUNOTHERAPY ADVERSE EVENTS IN POST TRANSPLANT PATIENTS Mechanism of action}

The majority of IO safety data are from studies of non-transplant patients; data from patients post- 
Table 1. Summary of case reports of use of immune checkpoint inhibitors in the post liver transplant setting

\begin{tabular}{|c|c|c|c|c|c|c|c|c|c|c|c|c|}
\hline Author & $\begin{array}{l}\text { Age } \\
\text { (years) }\end{array}$ & Indication for LT & $\begin{array}{l}\text { Indication } \\
\text { for } 10 \text { post- } \\
\text { LT }\end{array}$ & $\begin{array}{l}\text { Time } \\
\text { from LT } \\
\text { to ICI } \\
\text { (years) }\end{array}$ & $\begin{array}{l}\text { ICI therapy } \\
\text { used }\end{array}$ & $\begin{array}{l}\text { Immune } \\
\text { suppression } \\
\text { given at time } \\
\text { of ICI }\end{array}$ & $\begin{array}{l}\text { Graft } \\
\text { PDL1 } \\
\text { status }\end{array}$ & $\begin{array}{l}\text { Best } \\
\text { response } \\
\text { to ICI }\end{array}$ & $\begin{array}{l}\text { Liver } \\
\text { toxicity }\end{array}$ & $\begin{array}{l}\text { Time to } \\
\text { develop } \\
\text { toxicity }\end{array}$ & $\begin{array}{l}\text { Treatment } \\
\text { of toxicity }\end{array}$ & $\begin{array}{l}\text { Response to } \\
\text { treatment of } \\
\text { toxicity }\end{array}$ \\
\hline Kumar et al. ${ }^{[32]} 2019$ & 64 & $\mathrm{HCC}$ & $\mathrm{HCC}$ & 2 & Nivolumab & NA & NA & NA & TCMR & 1 week & $\begin{array}{l}\text { High dose } \\
\text { steroids, ATG, } \\
\text { PLEX }\end{array}$ & $\begin{array}{l}\text { Improvement of } \\
\text { rejection }\end{array}$ \\
\hline Gomez et al. ${ }^{[37]} 2018$ & 61 & $\mathrm{HCC}$ & $\mathrm{HCC}$ & 2 & Nivolumab & NA & NA & NA & TCMR & 1 month & Prednisone & $\begin{array}{l}\text { Improvement of } \\
\text { rejection }\end{array}$ \\
\hline Anugwom et al. ${ }^{[38]} 2020$ & 62 & $\mathrm{HCC}$ & $\mathrm{HCC}$ & 5 & Nivolumab & Tacrolimus & NA & NA & $\begin{array}{l}\text { Immune } \\
\text { hepatitis }\end{array}$ & 2 months & Steroids & $\begin{array}{l}\text { Worsening of } \\
\text { hepatitis }\end{array}$ \\
\hline Varkaris et al. ${ }^{[39]} 2017$ & 70 & $\mathrm{HCC}$ & $\mathrm{HCC}$ & 8 & Pembrolizumab & Tacrolimus & NA & POD & no & - & - & - \\
\hline Friend et al. ${ }^{[40]} 2017$ & 20 & $\mathrm{HCC}$ & $\mathrm{HCC}$ & 3 & Nivolumab & Sirolimus & Pos & NA & $\begin{array}{l}\text { TCMR + } \\
\text { AMR }\end{array}$ & $<1$ month & $\begin{array}{l}\text { Pulse high } \\
\text { dose steroids, } \\
\text { IVIG }\end{array}$ & $\begin{array}{l}\text { No response, } \\
\text { death }\end{array}$ \\
\hline Friend et al. ${ }^{[40]} 2017$ & 14 & $\mathrm{HCC}$ & $\mathrm{HCC}$ & 2 & Nivolumab & Tacrolimus & Pos & NA & $\begin{array}{l}\text { TCMR + } \\
\text { AMR }\end{array}$ & $<1$ month & $\begin{array}{l}\text { High dose } \\
\text { steroids }\end{array}$ & $\begin{array}{l}\text { No response, } \\
\text { death }\end{array}$ \\
\hline Rammohan et al. ${ }^{[4]]} 2018$ & 57 & $\mathrm{HCC}$ & $\mathrm{HCC}$ & 4 & $\begin{array}{l}\text { Pembrolizumab + } \\
\text { sorafenib }\end{array}$ & $\begin{array}{l}\text { mTOR inhibitor, } \\
\text { tacrolimus }\end{array}$ & NA & $C R$ & No & - & - & - \\
\hline Amjad et al. ${ }^{[42]} 2020$ & 62 & $\mathrm{HCC}$ & $\mathrm{HCC}$ & 1.3 & Nivolumab & Tacrolimus & NA & $\mathrm{CR}$ & No & - & - & - \\
\hline DeLeon et al. ${ }^{[43]} 2018$ & 56 & $\mathrm{HCC}$ & $\mathrm{HCC}$ & 2.7 & Nivolumab & Tacrolimus & NA & POD & No & - & - & - \\
\hline DeLeon et al. ${ }^{[43]} 2018$ & 55 & $\mathrm{HCC}$ & $\mathrm{HCC}$ & 7.8 & Nivolumab & MMF, sirolimus & $0 \%$ & POD & No & - & - & - \\
\hline DeLeon et al. ${ }^{[43]} 2018$ & 34 & $\mathrm{HCC}$ & $\mathrm{HCC}$ & 3.7 & Nivolumab & Tacrolimus & $0 \%$ & POD & No & - & - & - \\
\hline DeLeon et al. ${ }^{[43]} 2018$ & 63 & $\mathrm{HCC}$ & $\mathrm{HCC}$ & 1.2 & Nivolumab & Tacrolimus & NA & NA & No & - & - & - \\
\hline DeLeon et al. ${ }^{[43]} 2018$ & 68 & $\mathrm{HCC}$ & $\mathrm{HCC}$ & 1.1 & Nivolumab & Sirolimus & $30 \%$ & POD & TCMR & $<1$ month & NA & $\begin{array}{l}\text { NA (died due to } \\
\text { POD) }\end{array}$ \\
\hline Gassmann et al. ${ }^{[45]}$ & 53 & $\mathrm{HCC}$ & $\mathrm{HCC}$ & 3 & Nivolumab & Everolimus & NA & POD & TCMR & 2 weeks & $\begin{array}{l}\text { Steroids, } \\
\text { tacrolimus }\end{array}$ & $\begin{array}{l}\text { No response, } \\
\text { death }\end{array}$ \\
\hline De Toni et al. ${ }^{[46]} 2017$ & 41 & $\mathrm{HCC}$ & $\mathrm{HCC}$ & 1 & Nivolumab & Tacrolimus & NA & POD & No & - & - & - \\
\hline Al Jarroudi et al. ${ }^{[50]} 2020$ & 70 & $\mathrm{HCC}$ & $\mathrm{HCC}$ & 3 & Nivolumab & Tacrolimus & NA & NA & $\begin{array}{l}\text { Immune } \\
\text { hepatitis vs. } \\
\text { graft } \\
\text { rejection }\end{array}$ & 2 months & $\begin{array}{l}\text { High-dose } \\
\text { steroids }\end{array}$ & NA \\
\hline Al Jarroudi et al. ${ }^{[50]} 2020$ & 62 & $\mathrm{HCC}$ & $\mathrm{HCC}$ & 2 & Nivolumab & Tacrolimus & NA & POD & No & - & - & - \\
\hline Al Jarroudi et al. ${ }^{[50]} 2020$ & 66 & $\mathrm{HCC}$ & $\mathrm{HCC}$ & 5 & Nivolumab & Tacrolimus & NA & POD & No & - & - & - \\
\hline Kuo et al. ${ }^{[34]} 2018$ & 62 & $\mathrm{HCC}$ & Melanoma & 4.5 & $\begin{array}{l}\text { Ipilimumab then } \\
\text { pembrolizumab }\end{array}$ & Sirolimus & NA & PR & No & - & - & - \\
\hline
\end{tabular}




\begin{tabular}{|c|c|c|c|c|c|c|c|c|c|c|c|c|}
\hline Schvartzman et al. ${ }^{[35]} 2017$ & 35 & Biliary atresia & Melanoma & 20 & Pembrolizumab & Steroids, MMF & NA & $C R$ & $\begin{array}{l}\text { Immune } \\
\text { hepatitis }\end{array}$ & 1 month & Steroids, MMF & $\begin{array}{l}\text { Improvement of } \\
\text { hepatitis }\end{array}$ \\
\hline Ranganath et al. ${ }^{[36]} 2015$ & 59 & Cirrhosis & Melanoma & 8 & Ipilimumab & Tacrolimus & NA & POD & No & - & - & - \\
\hline Dueland et al. ${ }^{[47]} 2017$ & 67 & Melanoma & Melanoma & 1.5 & Ipilimumab & Prednisone & NA & POD & TCMR & $<1$ month & $\begin{array}{l}\text { High-dose } \\
\text { steroids, MMF, } \\
\text { sirolimus }\end{array}$ & $\begin{array}{l}\text { Improvement of } \\
\text { rejection }\end{array}$ \\
\hline DeLeon et al. ${ }^{[43]} 2018$ & 63 & Cholangiocarcinoma & Melanoma & 3.1 & Pembrolizumab & MMF, prednisone & $25 \%$ & NA & TCMR & $<1$ month & $\begin{array}{l}\text { ATG, MMF, } \\
\text { tacrolimus, } \\
\text { prednisone }\end{array}$ & $\begin{array}{l}\text { Improvement of } \\
\text { rejection }\end{array}$ \\
\hline Morales et al. ${ }^{[44]} 2015$ & 67 & $\mathrm{HCC}$ & Melanoma & 8 & Ipilimumab & Rapamycin & NA & PR & $\begin{array}{l}\text { Immune } \\
\text { hepatitis }\end{array}$ & 2 months & None & $\begin{array}{l}\text { Improvement of } \\
\text { hepatitis }\end{array}$ \\
\hline DeLeon et al. ${ }^{[43]} 2018$ & 54 & $\mathrm{HCC}$ & Melanoma & 5.5 & Pembrolizumab & Everolimus, MMF & $0 \%$ & $C R$ & No & - & - & - \\
\hline Chen et al. ${ }^{[33]} 2019$ & 61 & Cirrhosis & CRC & 2.5 & Pembrolizumab & $\begin{array}{l}\text { Prednisone } \\
(1 \mathrm{mg} / \mathrm{kg}) \\
\text { tacrolimus }\end{array}$ & NA & PR & No & - & - & - \\
\hline Biondani et al. ${ }^{[48]} 2018$ & 54 & Cirrhosis & $\begin{array}{l}\text { Metastatic } \\
\text { Squamous } \\
\text { NSCLC }\end{array}$ & 13 & Nivolumab & $\begin{array}{l}\text { Prednisone, } \\
\text { tacrolimus, } \\
\text { everolimus }\end{array}$ & NA & POD & No & - & - & - \\
\hline Lee et al. ${ }^{[49]} 2019$ & 73 & $\mathrm{HCC}$ & $\begin{array}{l}\text { Cutaneous } \\
\text { SCC }\end{array}$ & 12 & Nivolumab & Everolimus & NA & NA & $\begin{array}{l}\text { TCMR + } \\
\text { AMR }\end{array}$ & 1 month & $\begin{array}{l}\text { High-dose } \\
\text { steroids, } \\
\text { everolimus, } \\
\text { MMF }\end{array}$ & $\begin{array}{l}\text { Improvement in } \\
\text { TCMR, but } \\
\text { persistent AMR }\end{array}$ \\
\hline
\end{tabular}

HCC: Hepatocellular carcinoma; CRC: colorectal carcinoma; NSCLC: non-small cell lung cancer; ATG: anti-thymocyte globulin; PLEX: plasma exchange; TCMR: T-cell mediated rejection; AMR: antibody mediated rejection.

transplant are scarce. The mechanism of action of IO agents likely limits their use in the post-transplant setting. It is apparent that the PD-1/PD-L1 and CTLA4 checkpoint pathways contribute to immune tolerance of a transplanted organ ${ }^{[1]]}$. Immunofluorescence analysis of graft biopsies typically shows high expression of PD-1 and PD-L1 in all graft, highlighting the role of immune checkpoints in graft immune tolerance. Additionally, a mouse orthotopic liver transplant model showed PD-L1 to be expressed by hepatocytes and cholangiocytes of liver allografts, while PD-1 expression was increased on allograft infiltrating $\mathrm{T}$ cells ${ }^{[2]}$. Therefore, it raises concern that administration of ICIs may increase the risk of T-cell mediated rejection (TCMR).

When characterizing graft rejection, we generally consider three subtypes: chronic rejection, antibody-mediated rejection (AMR) and TCMR ${ }^{[4,63]}$. Graft rejection associated with immunotherapy is an acute process that is believed to T-cell mediated given the loss of immune-tolerance from PD-1/PD-L1 or CTLA-4 pathway blockade. Histological features of cellular rejection include T-cell infiltration and inflammation of the portal, bile duct, and venous endothelial systems ${ }^{[63]}$. As expected all confirmed cases of graft rejection in Table 1 had at least some component of ACMR, with some AMR. 
Of the 28 LT cases shown in Table 1, 7 were tested for PD-L1 status. Four of these 7 cases showed PD-L1 positivity, and all 4 cases (100\%) resulted in graft rejection. There is emerging thought around using PD-L1 expression as a marker of safety for anti-PD1 therapy in transplant patients. Mouse models suggest that PD$1 / \mathrm{PD}-\mathrm{L} 1$ activity, which is a negative costimulatory signal, is necessary for allograft tolerance ${ }^{[64,65]}$. In pancreatic islet transplantation in mice, PD-L1 deficiency was associated with accelerated graft rejection due to T-cell activation and infiltration. In another small study of 5 solid organ transplant patients, the absence of PD-L1 expression in their respective grafts was used as a marker for anti-PD-1 toripalimab therapy. None of the patients in this study developed graft rejection. From this perspective, a lack of PD-L1 expression in the graft appears beneficial for graft tolerance in the setting of ICI therapy; and in the face of active PD-L1 expression, ICI therapy would jeopardize the graft. Based on this small retrospective study, the PD-L1 status of the allograft may be a useful marker of graft rejection from PD-L1/PD-1 blockade. Therefore, we hypothesize that grafts with a higher baseline level of PD-L1/PD-1 activity would be particularly sensitive to PD-L1/PD-1 inhibition such that the risk of graft rejection is much higher than grafts that are PD-L1/PD-1 negative. This hypothesis calls for investigation and confirmation in a larger study.

\section{Rates of rejection}

Even though there is a risk of allograft rejection, IO has been attempted in selected patients post-transplant, as we have outlined above. However, this may come at the cost of an increased risk of graft rejection. A systematic search of 29 patients treated with ICIs following solid organ transplantation by Gassmann et al.$^{[4]}$ revealed that graft loss was observed in $36 \%$ of orthotopic liver transplant and $54 \%$ of kidney graft recipients. The majority of these patients suffered graft loss even on high dose immunosuppression. The predominant ICI used in this series was nivolumab. A larger systematic review of 83 patients published in 2020 by d'Izarny-Gargas et al. ${ }^{[66]}$ showed similar results. Allograft rejection was observed in nearly $40 \%$ of patients (43\% of kidney graft recipients and $37 \%$ of liver transplant recipients), and over two-thirds of those patients progressed to end-stage organ failure. Only two patients had a complete recovery on emergency antirejection treatment. The average time to graft rejection from first ICI use was 5.6 weeks, similar to other reported cases in the literature, and alarmingly, the median OS of the 83 patients was a mere 36 weeks. The majority of the patients $(73 \%)$ were treated with anti-PD-1/PD-L1 inhibitors. In the investigators' multivariate analysis, two factors were associated with a lower risk of rejection: treatment with at least one drug other than corticosteroids for baseline immunosuppression and being at least 8 years out from transplant. Although it is hard to draw a firm conclusion from small uncontrolled trials, the findings reviewed here raise the possibility of using IO safely in patients receiving nonsteroidal antirejection medicines (such as calcineurin inhibitors and mTOR inhibitors).

Of the 28 cases presented in Table 1, there were biopsy-proven acute graft rejections in 9 patients (32\%). These patients were generally treated with steroids and often with additional immunosuppression (i.e., tacrolimus, mycophenolate, ATG). This resulted in the resolution of graft rejection in 4 of the 9 cases. Three cases did not improve with immunosuppression and ultimately lead to the patients' demise. One case had an unknown response to immunosuppression. Interestingly, the 3 patients whose graft rejection did not reverse were all younger than 60 years of age $(14,20$, and 53), whereas those who recovered from their graft rejection were all over 60 years of age. This pattern of solid organ graft rejection has been seen commonly in liver and kidney transplant cases unrelated to ICI use; hence younger patients have a higher risk of graft rejection, perhaps owing to a more robust immune system ${ }^{[67-69]}$. It would be reasonable to consider that the use of IO therapy in younger populations may elicit a stronger T-cell mediated response that would more likely jeopardize the graft. 


\section{Timing of rejection}

As already mentioned, d'Izarny-Gargas et al. ${ }^{[6]]}$ showed lower rates of rejection in patients who had received a solid organ transplant several years before IO administration. Similarly, in the cases reviewed in Table 1, most graft rejection after ICI therapy occurred in patients who had transplant within 3 years, except one patient with cutaneous SCC who had a rejection from ICI at 12 years post-transplant. Among patients treated with ICI who did not develop rejection, transplant occurred 1 to 20 years from transplant. The median time between LT and ICI therapy was 2 years among patients who had subsequent graft rejection, vs. 4.5 years among those who did not. These lower rejection rates when patients are further out from transplant could be due to the development of immune tolerance of the grafted organ; once the early posttransplant period is over, weaker immunosuppression is needed. Thus, the use of ICI may be safer in the late post-transplant period. However, there have been reports of graft rejection with ICI use up to 25 years after transplant ${ }^{[61]}$. More controlled trials are needed to ascertain the optimal timing of ICI administration in the post-transplant setting.

\section{$\mathrm{ICI}$ differences}

Anti-CTLA4 therapy has been associated with greater toxicity than PD-1 and PD-L1 inhibitors. However, the degree of anti-CTLA4 agent efficacy and safety post-transplant is particularly unclear due to limited application in this setting. Some case series suggest lower rates of graft rejection with anti-CTLA4 therapy than with PD- 1 and PD-L1 therapies. In a small series of published case reports, it was observed that 4 of 10 patients had graft rejection on receipt of PD- 1 therapy, whereas 0 of 3 patients treated with anti-CTLA4 ipilimumab experienced graft rejection. There are some data suggesting that the PD-1 pathway plays a larger role in graft immune tolerance, but it is difficult to draw definitive conclusions from these data because of the small and unmatched numbers of patients receiving each treatment type ${ }^{[61]}$. In a systematic review published in 2020, nivolumab was associated with the highest rate of graft rejection $(52 \%, 12 / 23)$, followed by pembrolizumab $(26 \%, 4 / 15)$ and ipilimumab $(25 \%, 3 / 12)^{[70]}$. However, these findings were not statistically significant. Although there may be a theoretical basis for anti-CTLA4 therapies being better tolerated from a rejection standpoint, this would have to be explored in further studies.

\section{Treatment and outcomes of rejection}

Graft rejection is associated with ICI, even when aggressive immunosuppressant therapy is applied. In their systematic review, Gassmann et al. ${ }^{[45]}$ showed the occurrence of end-stage organ failure secondary to rejection in $71 \%$ of 29 patients. Another review of 20 patients suggested lower rates of rejection (35\%) but a higher mortality rate $(38 \%)$ in patients experiencing graft rejection ${ }^{[7]}$. Although these numbers may sound alarming, it is difficult to define the absolute risk of graft rejection associated with ICI in the absence of strict patient selection criteria and randomized controlled trials. The majority of the published data are derived from case reports or series with small sample sizes and likely significant heterogeneity in patient characteristics and treatment, such as patient age, type of immunosuppressant therapy received, number of years out from transplant, and dose and timing of ICI use post-transplant.

\section{FUTURE DIRECTIONS}

ICIs appear to demonstrate good anticancer efficacy in the transplant setting but pose a significant risk of graft rejection. The paucity of data generated from ICI use post-transplant - most of which are from individual cases - makes it hard to devise recommendations for their use in this setting. Controlled studies are needed to assess the efficacy and safety of these agents peri-transplant, during which the following should be explored: age of recipient; timing of ICI use in relation to LT; and the use of biomarkers (such as PD-1/PD-L1 expression in the graft) to predict ICI therapy. A sequential series of clinical trials might start with a prospective early phase study to evaluate neoadjuvant IO therapy pre-LT. Patients who have had a response to ICI therapy for HCC (i.e., in the setting of advanced HCC) may be evaluated for LT, and those 
who are candidates for LT may be enrolled for transplant in 6 or 12 months following the last dose of ICI. During this period, no further IO therapies is allowed, although bridging therapies (i.e., locoregional therapies) may be employed. This study would help determine a safe duration between IO and LT. Rates of graft rejection would be evaluated as the primary endpoint; secondary endpoints include PFS and OS. If this neoadjuvant approach is shown to be safe, further studies can be considered for post-transplant IO therapy. Once the appropriate patient characteristics are defined, a treatment algorithm may be generated to guide clinicians in the use of ICIs in the peri-transplant setting with the aim of providing effective IO to patients that can and should be allowed to benefit.

\section{DECLARATIONS}

\section{Acknowledgments}

We would like to thank Marion L Hartley for her invaluable edits to this manuscript.

\section{Authors' contributions}

Made substantial contributions to conception and design of the study and performed data analysis and interpretation: Yin C, Baba T, He AR, Smith C

\section{Availability of data and materials}

Not applicable.

\section{Financial support and sponsorship}

None.

\section{Conflicts of interest}

All authors declared that there are no conflicts of interest.

\section{Ethical approval and consent to participate}

Not applicable.

\section{Consent for publication}

Not applicable.

\section{Copyright}

(c) The Author(s) 2021.

\section{REFERENCES}

1. Kanwal F, Singal AG. Surveillance for hepatocellular carcinoma: current best practice and future direction. Gastroenterology 2019;157:54-64. DOI PubMed PMC

2. White DL, Thrift AP, Kanwal F, Davila J, El-Serag HB. Incidence of hepatocellular carcinoma in all 50 United States, from 2000 through 2012. Gastroenterology 2017;152:812-20.e5. DOI PubMed PMC

3. Lucey MR, Terrault N, Ojo L, et al. Long-term management of the successful adult liver transplant: 2012 practice guideline by the American Association for the study of liver diseases and the American Society of transplantation. Liver Transpl 2013;19:3-26. DOI PubMed

4. Ho CM, Chen HL, Hu RH, Lee PH. Harnessing immunotherapy for liver recipients with hepatocellular carcinoma: a review from a transplant oncology perspective. Ther Adv Med Oncol 2019;11:1758835919843463. DOI PubMed PMC

5. Kumar V, Shinagare AB, Rennke HG, et al. The safety and efficacy of checkpoint inhibitors in transplant recipients: a case series and systematic review of literature. Oncologist 2020;25:505-14. DOI PubMed PMC

6. Walunas TL, Lenschow DJ, Bakker CY, et al. CTLA-4 can function as a negative regulator of T cell activation. Immunity 1994;1:40513. DOI PubMed

7. Hodi FS. Cytotoxic T-lymphocyte-associated antigen-4. Clin Cancer Res 2007;13:5238-42. DOI PubMed

8. Lubienski A. Hepatocellular carcinoma: interventional bridging to liver transplantation. Transplantation 2005;80:S113-9. DOI PubMed

9. Cardarelli-Leite L, Hadjivassiliou A, Klass D, et al. Current locoregional therapies and treatment strategies in hepatocellular 
carcinoma. Curr Oncol 2020;27:S144-51. DOI PubMed PMC

10. Llovet JM, Ricci S, Mazzaferro V, et al; SHARP Investigators Study Group. Sorafenib in advanced hepatocellular carcinoma. $N$ Engl J Med 2008;359:378-90. DOI

11. Network NCC. Hepatobiliary Cancers (Version 5.2020). In. Available from https://www.nccn.org/professionals/physician_gls/pdf/hepatobiliary.pdf. [Last accessed on 1 Jul 2021].

12. Eilard MS, Andersson M, Naredi P, et al. A prospective clinical trial on sorafenib treatment of hepatocellular carcinoma before liver transplantation. BMC Cancer 2019;19:568. DOI PubMed PMC

13. Castelli G, Burra P, Giacomin A, et al. Sorafenib use in the transplant setting. Liver Transpl 2014;20:1021-8. DOI PubMed

14. Nordness MF, Hamel S, Godfrey CM, et al. Fatal hepatic necrosis after nivolumab as a bridge to liver transplant for HCC: are checkpoint inhibitors safe for the pretransplant patient? Am J Transplant 2020;20:879-83. DOI PubMed

15. Schwacha-Eipper B, Minciuna I, Banz V, Dufour JF. Immunotherapy as a downstaging therapy for liver transplantation. Hepatology 2020;72:1488-90. DOI PubMed

16. El-khoueiry AB, Sangro B, Yau T, et al. Nivolumab in patients with advanced hepatocellular carcinoma (CheckMate 040): an openlabel, non-comparative, phase 1/2 dose escalation and expansion trial. Lancet 2017;389:2492-502. DOI PubMed PMC

17. Finn RS, Ryoo BY, Merle P, et al; KEYNOTE-240 investigators. Pembrolizumab as second-line therapy in patients with advanced hepatocellular carcinoma in KEYNOTE-240: a randomized, double-blind, phase III trial. J Clin Oncol 2020;38:193-202. DOI PubMed

18. Yau T, Kang YK, Kim TY, et al. Efficacy and safety of nivolumab plus ipilimumab in patients with advanced hepatocellular carcinoma previously treated with sorafenib: the CheckMate 040 randomized clinical trial. JAMA Oncol 2020;6:e204564. DOI PubMed PMC

19. Chuzi S, Tavora F, Cruz M, et al. Clinical features, diagnostic challenges, and management strategies in checkpoint inhibitor-related pneumonitis. Cancer Manag Res 2017;9:207-13. DOI PubMed PMC

20. Martins F, Sofiya L, Sykiotis GP, et al. Adverse effects of immune-checkpoint inhibitors: epidemiology, management and surveillance. Nat Rev Clin Oncol 2019;16:563-80. DOI PubMed

21. De Martin E, Michot JM, Papouin B, et al. Characterization of liver injury induced by cancer immunotherapy using immune checkpoint inhibitors. J Hepatol 2018;68:1181-90. DOI PubMed

22. Centanni M, Moes DJAR, Trocóniz IF, Ciccolini J, van Hasselt JGC. Clinical pharmacokinetics and pharmacodynamics of immune checkpoint inhibitors. Clin Pharmacokinet 2019;58:835-57. DOI PubMed PMC

23. Goldaracena N, Mehta N, Scalera I, et al. Multicenter validation of a score to predict prognosis after the development of HCC recurrence following liver transplantation. HPB (Oxford) 2019;21:731-8. DOI PubMed

24. Sapisochin G, Bruix J. Liver transplantation for hepatocellular carcinoma: outcomes and novel surgical approaches. Nat Rev Gastroenterol Hepatol 2017;14:203-17. DOI PubMed

25. Sapisochin G, Goldaracena N, Astete S, et al. Benefit of treating hepatocellular carcinoma recurrence after liver transplantation and analysis of prognostic factors for survival in a large Euro-American series. Ann Surg Oncol 2015;22:2286-94. DOI PubMed

26. de'Angelis N, Landi F, Carra MC, Azoulay D. Managements of recurrent hepatocellular carcinoma after liver transplantation: a systematic review. World J Gastroenterol 2015;21:11185-98. DOI PubMed PMC

27. Zhu AX, Finn RS, Edeline J, et al. Pembrolizumab in patients with advanced hepatocellular carcinoma previously treated with sorafenib (KEYNOTE-224): a non-randomised, open-label phase 2 trial. Lancet Oncol 2018;19:940-52. DOI PubMed

28. Finn RS, Qin S, Ikeda M, et al; IMbrave150 Investigators. Atezolizumab plus bevacizumab in unresectable hepatocellular carcinoma. N Engl J Med 2020;382:1894-905. DOI PubMed

29. Green AC, Olsen CM. Increased risk of melanoma in organ transplant recipients: systematic review and meta-analysis of cohort studies. Acta Derm Venereol 2015;95:923-7. DOI PubMed

30. Suresh K, Naidoo J, Lin CT, Danoff S. Immune checkpoint immunotherapy for non-small cell lung cancer: benefits and pulmonary toxicities. Chest 2018;154:1416-23. DOI PubMed PMC

31. Furue M, Ito T, Wada N, Wada M, Kadono T, Uchi H. Melanoma and immune checkpoint inhibitors. Curr Oncol Rep 2018;20:29. DOI PubMed

32. Kumar S. 2235 nivolumab-induced severe allograft rejection in recurrent post-transplant hepatocellular carcinoma. Am J Gastroenterol 2019;114:S1251. DOI

33. Chen JA, Esteghamat N, Kim EJ, et al. PD-1 blockade in a liver transplant recipient with microsatellite unstable metastatic colorectal cancer and hepatic impairment. J Natl Compr Canc Netw 2019;17:1026-30. DOI PubMed

34. Kuo JC, Lilly LB, Hogg D. Immune checkpoint inhibitor therapy in a liver transplant recipient with a rare subtype of melanoma: a case report and literature review. Melanoma Res 2018;28:61-4. DOI PubMed

35. Schvartsman G, Perez K, Sood G, Katkhuda R, Tawbi H. Immune checkpoint inhibitor therapy in a liver transplant recipient with melanoma. Ann Intern Med 2017;167:361-2. DOI PubMed

36. Ranganath HA, Panella TJ. Administration of ipilimumab to a liver transplant recipient with unresectable metastatic melanoma. $J$ Immunother 2015;38:211. DOI PubMed

37. Gomez P, Naim A, Zucker K, Wong M. A case of hepatocellular carcinoma (HCC) immunotherapy inducing liver transplant rejection: 2416. Am J Gastroenterol 2018;113:S1347. DOI

38. Anugwom C, Leventhal T. Nivolumab-induced autoimmune-like cholestatic hepatitis in a liver transplant recipient. ACG Case Rep $J$ 2020;7:e00416. DOI PubMed PMC

39. Varkaris A, Lewis DW, Nugent FW. Preserved liver transplant after PD-1 pathway inhibitor for hepatocellular carcinoma. Am $J$ 
Gastroenterol 2017;112:1895-6. DOI PubMed

40. Friend BD, Venick RS, McDiarmid SV, et al. Fatal orthotopic liver transplant organ rejection induced by a checkpoint inhibitor in two patients with refractory, metastatic hepatocellular carcinoma. Pediatr Blood Cancer 2017;64:e26682. DOI PubMed

41. Rammohan A, Reddy MS, Farouk M, Vargese J, Rela M. Pembrolizumab for metastatic hepatocellular carcinoma following live donor liver transplantation: the silver bullet? Hepatology 2018;67:1166-8. DOI PubMed

42. Amjad W, Kotiah S, Gupta A, Morris M, Liu L, Thuluvath PJ. Successful treatment of disseminated hepatocellular carcinoma after liver transplantation with nivolumab. J Clin Exp Hepatol 2020;10:185-7. DOI PubMed PMC

43. DeLeon TT, Salomao MA, Aqel BA, et al. Pilot evaluation of PD-1 inhibition in metastatic cancer patients with a history of liver transplantation: the Mayo Clinic experience. J Gastrointest Oncol 2018;9:1054-62. DOI PubMed PMC

44. Morales RE, Shoushtari AN, Walsh MM, Grewal P, Lipson EJ, Carvajal RD. Safety and efficacy of ipilimumab to treat advanced melanoma in the setting of liver transplantation. J Immunother Cancer 2015;3:22. DOI PubMed PMC

45. Gassmann D, Weiler S, Mertens JC, et al. Liver allograft failure after nivolumab treatment-a case report with systematic literature research. Transplant Direct 2018;4:e376. DOI PubMed PMC

46. Toni EN, Gerbes AL. Tapering of immunosuppression and sustained treatment with nivolumab in a liver transplant recipient. Gastroenterology 2017;152:1631-3. DOI PubMed

47. Dueland S, Guren TK, Boberg KM, et al. Acute liver graft rejection after ipilimumab therapy. Ann Oncol 2017;28:2619-20. DOI PubMed

48. Biondani P, De Martin E, Samuel D. Safety of an anti-PD-1 immune checkpoint inhibitor in a liver transplant recipient. Ann Oncol 2018;29:286-7. DOI PubMed

49. Lee BT, Horwich BH, Chopra S, Ahearn A, Han HH. Checkpoint inhibitor-induced rejection of a liver allograft: a combination of acute T cell-mediated and antibody-mediated rejection. Liver Transpl 2019;25:1845-8. DOI PubMed

50. Jarroudi O, Ulusakarya A, Almohamad W, Afqir S, Morere JF. Anti-programmed cell death Protein 1 (PD-1) immunotherapy for metastatic hepatocellular carcinoma after liver transplantation: a report of three cases. Cureus 2020;12:e11150. DOI PubMed PMC

51. Robert C, Ribas A, Schachter J, et al. Pembrolizumab versus ipilimumab in advanced melanoma (KEYNOTE-006): post-hoc 5-year results from an open-label, multicentre, randomised, controlled, phase 3 study. Lancet Oncol 2019;20:1239-51. DOI PubMed

52. Robert C, Long GV, Brady B, et al. Nivolumab in previously untreated melanoma without BRAF mutation. $N$ Engl J Med 2015;372:320-30. DOI PubMed

53. Brahmer JR, Lacchetti C, Schneider BJ, et al; National Comprehensive Cancer Network. Management of immune-related adverse events in patients treated with immune checkpoint inhibitor therapy: American society of clinical oncology clinical practice guideline. J Clin Oncol 2018;36:1714-68. DOI PubMed PMC

54. Yau T, Park JW, Finn RS, et al. CheckMate 459: a randomized, multi-center phase III study of nivolumab (NIVO) vs sorafenib (SOR) as first-line (1L) treatment in patients (pts) with advanced hepatocellular carcinoma (aHCC). Ann Oncol 2019;30:v874-v5.

55. Wainberg ZA, Segal NH, Jaeger D, et al. Safety and clinical activity of durvalumab monotherapy in patients with hepatocellular carcinoma (HCC). J Clin Oncol 2017;35:4071. DOI

56. Yau T, Kang YK, Kim TY, et al. Nivolumab (NIVO) + ipilimumab (IPI) combination therapy in patients (pts) with advanced hepatocellular carcinoma (aHCC): Results from CheckMate 040. J Clin Oncol 2019;37:4012. DOI

57. Freites-Martinez A, Santana N, Arias-Santiago S, Viera A. Using the common terminology criteria for adverse events (CTCAE Version 5.0) to evaluate the severity of adverse events of anticancer therapies. Actas Dermosifiliogr (Engl Ed) 2021;112:90-2. DOI PubMed

58. Larkin J, Hodi FS, Wolchok JD. Combined nivolumab and ipilimumab or monotherapy in untreated melanoma. N Engl J Med 2015;373:1270-1. DOI PubMed

59. Horvat TZ, Adel NG, Dang TO, et al. Immune-related adverse events, need for systemic immunosuppression, and effects on survival and time to treatment failure in patients with melanoma treated with ipilimumab at memorial sloan kettering cancer center. $J$ Clin Oncol 2015;33:3193-8. DOI PubMed PMC

60. Ziemer M, Koukoulioti E, Beyer S, Simon JC, Berg T. Managing immune checkpoint-inhibitor-induced severe autoimmune-like hepatitis by liver-directed topical steroids. J Hepatol 2017;66:657-9. DOI PubMed

61. Kittai AS, Oldham H, Cetnar J, Taylor M. Immune checkpoint inhibitors in organ transplant patients. J Immunother 2017;40:277-81. DOI PubMed

62. Ono Y, Perez-Gutierrez A, Nakao T, et al. Graft-infiltrating PD-L1(hi) cross-dressed dendritic cells regulate antidonor T cell responses in mouse liver transplant tolerance. Hepatology 2018;67:1499-515. DOI PubMed PMC

63. Demetris AJ, Bellamy C, Hübscher SG, et al. 2016 comprehensive update of the banff working group on liver allograft pathology: introduction of antibody-mediated rejection. Am J Transplant 2016;16:2816-35. DOI PubMed

64. Wang L, Han R, Hancock WW. Programmed cell death 1 (PD-1) and its ligand PD-L1 are required for allograft tolerance. Eur J Immunol 2007;37:2983-90. DOI PubMed

65. Ma D, Duan W, Li Y, et al. PD-L1 Deficiency within islets reduces allograft survival in mice. PLoS One 2016;11:e0152087. DOI PubMed PMC

66. d'Izarny-Gargas T, Durrbach A, Zaidan M. Efficacy and tolerance of immune checkpoint inhibitors in transplant patients with cancer: a systematic review. Am J Transplant 2020;20:2457-65. DOI PubMed

67. Hartmann EL. Renal Transplantation in the older adult. In. Geriatric Nephrology Curriculum. American society of nephrology; 2009. Available from: https://www.asn-online.org/education/distancelearning/curricula/geriatrics/Chapter24.pdf [Last accessed on 11 Jun 2021]. 
68. Dogan N, Hüsing-Kabar A, Schmidt HH, Cicinnati VR, Beckebaum S, Kabar I. Acute allograft rejection in liver transplant recipients: incidence, risk factors, treatment success, and impact on graft failure. J Int Med Res 2018;46:3979-90. DOI PubMed PMC

69. Durand F, Levitsky J, Cauchy F, Gilgenkrantz H, Soubrane O, Francoz C. Age and liver transplantation. J Hepatol 2019;70:745-58. DOI PubMed

70. Fisher J, Zeitouni N, Fan W, Samie FH. Immune checkpoint inhibitor therapy in solid organ transplant recipients: a patient-centered systematic review. J Am Acad Dermatol 2020;82:1490-500. DOI PubMed

71. Hu B, Yang XB, Sang XT. Liver graft rejection following immune checkpoint inhibitors treatment: a review. Med Oncol 2019;36:94. DOI PubMed 